\title{
An overview of dentin bonding agents
}

\author{
Kadali Navyasri1, ${ }^{*}$, Rama Krishna Alla², Guduri Vineeth ${ }^{3}$, Suresh Sajjan MC ${ }^{4}$ \\ ${ }^{1}$ Lecturer, Department of Dental Materials, Vishnu Dental College, Bhimavaram, West Godavari, 534202, \\ Andhra Pradesh, India. \\ ${ }^{2}$ Assistant Professor, Department of Dental Materials, Vishnu Dental College, Bimavaram, West Godavari, \\ 534202, Andhra Pradesh, India. \\ ${ }^{3}$ Assistant Professor, Department of Prosthodontics, Vishnu Dental College, Bimavaram, West Godavari, \\ 534202, Andhra Pradesh, India. \\ 4Professor, Department of Prosthodontics, Vishnu Dental College, Bhimavaram, West Godavari, 534202, \\ Andhra Pradesh, India.
}

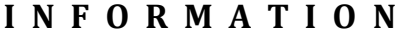

\section{Article History}

Received 14 October 2019

Received revised

02 November 2019

Accepted 03 November 2019

Available online

15 November 2019

\section{K E Y W O R D S}

Bonding agents

Adhesives

Primers,

Conditioning agents

Self-etch adhesives

Total-etch.

\section{A B S T R A C T}

From the past, there has been a lot of use of the bonding agents in restorative dentistry. Choosing of bonding systems has become a challenge for the clinicians as there was a lot of advances regarding the usage of bonding agents. Each successive modification in the formulae has led to the classification of the bonding system into many "generations". During the past few years, these bonding agents have been replaced by the same systems that are used on dentin. This change occurred because of the benefit of bonding resin to both enamel and dentin. Extensive research is still on the way to develop the best adhesive system that can produce reliable and permanent bonds to dentin.

\section{Introduction}

In dentistry, composites are widely used esthetic restorative materials over six decades [1]. The essential components of dental composites include resin matrix, organic/inorganic fillers, and coupling agents. The composition of dental composites is given in Table 1 [2]. The advantages of dental composite materials include improved strength, abrasion resistance, translucency, ease of application, and polishability. These qualities made them rapidly increased their use in the first decade after being introduced and continues to increase their popularity $[3,4]$. However, the major disadvantage with the composites is their poor bonding mechanism to the natural tooth. Numerous researchers developed various adhesive resins to provide an appropriate bonding between the composite resin and natural tooth. These early adhesive systems necessitate etching of the natural tooth with certain acids followed by treating with primers and/or conditioning agents [2].

Bonding agents can bring a strong bond between the composite and the tooth structure to withstand mechanical forces and stress. The success of adhesives depends on their ability to adhere to the natural tooth on one side and the composite restoration on the other side. The bonding can be achieved 


\begin{tabular}{cll}
\hline S.No. & Ingredient & Functions \\
\hline 1. & Polymer Matrix & Reactive Ingredieant. \\
& Eg: Bis GMA, UDMA & Possessess high viscosity. \\
2. & Diluent & Reduces viscosity of polymer matrix. \\
& Eg: TEGDMA & \\
3. & Amines & Activator systems \\
4. & Benzoyl peroxide, Benzoin methyl ethers and Cam- & Initiator systems for chemical, UV light \\
& phoroquinone. & and Visible light activated respectively. \\
5. & Butylated hydroxy toulene & Photoinhibitor \\
6. & Titania, Alumina etc., & Optical Modifiers \\
7. & Fillers & Increases strength and hardness. \\
& Eg: Ground quartz, pyrolytic silica, barium glasses, & Reduces CoTE. \\
& aluminum silicate, and colloidal silca. & \\
8. & Coupling agent & Provides bonding between fillers and poly- \\
\hline Table 1. Composition of dental composites & mer matrix. \\
\hline
\end{tabular}

with enamel and dentin, or both by micromechanical interlocking along with chemical bonding. Whereas, the bonding between the composite resin restoration and a bonding agent is attained by copolymerization of the adhesive resin with the resin matrix of composite materials [5,6]. Two different types of bonding agents have been developed. They include enamel bonding agents (EBA)and dentin bonding agents (DBA). The objective of this review is to discuss numerous bonding mechanisms and emphasize the various bonding agents developed in the field of adhesive dentistry to provide bonding with the natural tooth.

\subsection{History and evolution}

The use of dentin bonding agents markedly reduces the need to provide mechanical retention through dovetails, grooves, undercuts, sharp internal angles which in turn helps in conservation of sound tooth structure. The main reason for the success of aesthetic restorative materials is these adhesive systems[7]. In the late 1960s, Buonocore proposed that boning to dentin was possible[8,9]. In the 1970s, using scanning electron microscope, Eick identified the presence of a smear layer on the dentine surface[10]. He reported that the smear layer is blocking and interfering in bonding to dentin. In the 1980s, the total-etch concept was introduced by the development of etch and rinse systems. In 1982, Nakabayashi demonstrated the concept of hybrid layer formation on the dentin s u r fa ce
[11]. In the 1990s, the three-step total-etch system was developed. In Late 1990s original bonding systems evolved to multi-step systems. Further research leads to simplification of the application procedure to reduce manipulation time [7].

\section{Adhesion mechanisms}

Adhesion occurs when two, unlike molecules, join together on being brought into contact due to force of attraction between them [2]. The material which is used to produce adhesion is called as an "adhesive" and the substance to which adhesive is applied is called as an "adherent" $[2,5,12]$. The following are the adhesion mechanisms that are commonly employed in dentistry.

\subsection{Mechanical adhesion}

The interlocking of the adhesive with irregularities on the surface of the substrate or adherend. If the surface irregularities are responsible for bonding and having dimensions of only a few micrometres, the process is known as "micromechanical attachment". This is different from macro-mechanical attachment, which forms the basis of retention for many filling materials, using undercut cavities [2].

\subsection{Adsorption adhesion}


It occurs due to the chemical interaction between the adhesive and the adherend. Forces may be primary (ionic and covalent), secondary (hydrogen, dipole interaction), and vanderwaal's valence forces.

\subsection{Diffusion adhesion}

Interlocking between mobile molecules such as adhesion of two Polymers.

\subsection{Electrostatic adhesion}

An electrical double bond layer at the interface of metal with a polymer that is part of the total bonding system.

The bonding mechanism is explained in the following steps [5];

- Dissolution or adequate removal of the smear layer from enamel and dentin.

- Maintenance of the dentin collagen matrix.

- Good wetting.

- Efficient monomer diffusion and penetration.

- Polymerization within the tooth structure.

- Copolymerization with the resin composite matrix.

\section{Bonding agents}

EBAs consist of different dimethacrylates from resins of composites like bisphenyl glycidyl methacrylate (bis-GMA) with diluting monomers such as triethylene glycol dimethacrylate (TEGDMA)to control viscosity and to improve wetting. DBAs include etchants, resin monomers, solvents, initiators, inhibitors, fillers, and other ingredients $[5,13]$.

\section{Composition of bonding agents include [5];}

a. Etchant-37\% phosphoric acid.

b. Primers-HEMA (2-hydroxyethyl methacrylate) is a widely used primer monomer because of its high hydrophilicity and solvent like nature.

c. Solvents-The most commonly used solvents are water, ethanol, and acetone. Solvent has a specific contribution to improve bond adhesion.

d. Adhesives- Adhesive resins mostly composed of mainly of hydrophobic dimethacrylates such as bis-GMA, TEGDMA, and urethane dimethacrylates (UDMA).

e. Initiators- Polymerization can be initiated through a photoinitiator system consisting of the photose- nsitizer (e,g., camphoroquinone) and an activator (e.g., tertiary amine) for a self-cure resin system with an initiator such as benzoyl peroxide.

f. Fillers-silica particles.

g. Other ingredients like glutaraldehyde act as desensitizer, paraben used as antimicrobials, fluoride to prevent secondary caries, and chlorhexidine to prevent collagen degradation.

\subsection{Chemistry}

Chemistry is explained by the formula M-R-X [2,5], where ' $M$ ' is the methacrylate group that reacts with the resin matrix, ' $R$ ' is the spacer, and ' $X$ ' is the functional group for adhesion to tooth tissue.

\subsection{Generations of dentin bonding agents}

\subsubsection{First-generation dentin bonding agents}

Buonocore et al., (1956) demonstrated glycerol phosphoric acid dimethacrylate containing resin and cyanoacrylates to bond to acid-etched dentin. Hydrophilic phosphate group from the glycerol phosphoric acid dimethacrylate resin that increases bonding with Ca ions of the hydroxyapatite. The methacrylate groups were then able to bond to restorative acrylic resin [2]. However, the clinical results with these systems were poor. Commercial products of firstgeneration bonding agents were Scotch bond, Cervident, palakov, etc.

\subsubsection{Second generation bonding agents}

These systems were introduced in the late 1970s, the majority of these are "halo phosphorous esters" of unfilled acrylic resins such as bis-GMA or HEMA. The Second-generation systems bonded to dentin by ionic bonding to $\mathrm{Ca}$ by chlorophosphate groups. They were highly soluble in oral fluids, and moisture from dentin itself could result in debonding from the dentin and causing microleakage. The bond strength to dentin was weak and unreliable [2]. Commercial products from second-generation bonding agents include Clearfil and Prisma Universal Bond.

\subsubsection{Third-generation bonding agents}

The third generation of adhesive systems used a dentin conditioning step as well as an intermediate primer in conjunction with a bonding agent. The conditioning 
agents either modify or remove the smear layer before the placement of adhesive resins and attempts have been made to bond chemically with the calcium of dentin. Bowen developed these and used a $2.5 \%$ of nitric acid or ferric oxalate dentin conditioner followed by treatments of NTG-GMA and PMDM (Pyromellitic di anhydrate and 2-hydroxy ethyl methacrylate). This system was later modified by replacing ferric oxalate with aluminumoxalate [2].

\subsubsection{Composition of third-generation bonding systems}

- Conditioner: phosphoric acid with aluminum oxalate and nitric acid.

- $\quad$ Mirage bond

Dentin conditioner: HNO3 and NPG-GMA:2.5\%. Primer: PMDM.

- Gluma bonding system

Dentin conditioner: EDTA.

Primers: HEMA + Glutaraldehyde

- Scotch bond - II.

Dentin conditioner: Maleic acid and HEMA. Primers: BIS-GMA + HEMA.

- Prisma universal bond-III: This is designed to bond both the inorganic and organic parts of dentin.

Till the third-generation, concepts for dentin adhesion were based on bonding via resin tag formation in the tubules of conditioned dentin, the formation of precipitate on pretreated dentin surfaces followed by chemical or mechanical bonding of resin and chemical union to either inorganic or organic components of the dentin [2].The number of clinical steps involved with the newer generation bonding agents was mentioned in table 2 and 3.

\subsubsection{Fourth-generation bonding agents}

Fourth-generation systems involve three steps which include acid etchant application followed by the application of primer and application of actual bonding agent or bonding resin. A new wet bonding concept was introduced by Kanca [14] and Gwinettet et al. when acetone/alcohol-based primers are applied to demineralised dentine, water diffuses from wet dentine into the acetone, while the acetone diffuses into the demineralised dentine matrix. This chemical dehydration of the collagen network caused by the substitution of water by acetone increases the modulus of elasticity [15-18].
The bond strength of the fourth-generation bonding agents is more compared to the previous generations due to the formation of hybrid layer. It is an acid resistant admixture of polymer and tooth structure components creating a resin-dentin composite. The concept of hybridization is to improve the bond strength and also to provide better dentine seal. This can be achieved by the application of a hydrophilic primer solution that can infiltrate the exposed collagen network forming the hybrid layer. This can markedly reduce microleakage compared to the other bonding systems $[13,19]$.

\subsubsection{Commercial products:}

- All bond,

- Scotch bond

- Scotch bond multipurpose, 3M, USA. Conditioner: Maleic acid-10\%. Primer: Aqueous solution of HEMA and copolymer.

- PermaQuick, Ultradent.

- ProBond, Dentsply.

- $\quad$ Liner bond-II, Kuraray, Japan.

\subsubsection{Fifth-generation bonding agent}

Application of fifth-generation bonding agents involves a two-step procedure. A simplified method which combines the primer and adhesives into one application. It includes etching, which is usually done with $30 \%$ to $40 \%$ phosphoric acid that rinses away, promotes the dissolution of enamel rods thereby creating microporosities that are filled by bonding agents through capillary action and then followed by polymerization of the resin. In this case, phosphoric acid treatment exposes collagen network that is nearly devoid of hydroxyapatite. Bonding occurs by diffusion and infiltration of the resin within the collagen mess, forming a hybrid layer. This hybrid layer will provide micromechanical retention to the restoration. To facilitate clinical use, the fifth-generation system consists of a single bottle system; combined the primer and adhesives into one solution to be applied after etching enamel and dentin simultaneously. Fifth-generation bonding agents generally contain BIS-GMA, HEMA, GPDM, ethanol, barium, aluminum borosilicate glass, fumed silica, sodium, hexafluorosilicate, camphoroquinone [20]. The commercial products of this generation bonding systems include One-Coat Bond (Coltène Whaledent, Switzerland), Prime and bond (Dentsply-Detrey, Germany), Opti bond solo (Kerr, USA), Scotch bond multipurpose single bond -3M (Kuraray, Japan), etc. 


\begin{tabular}{|c|c|c|c|}
\hline $\begin{array}{l}\text { Three-step } \\
\text { (fourth-generation) }\end{array}$ & $\begin{array}{l}\text { Two-step } \\
\text { (fifth-generation) }\end{array}$ & $\begin{array}{l}\text { Two-step } \\
\text { (sixth-generation) }\end{array}$ & $\begin{array}{l}\text { One-step } \\
\text { (seventh-generation) }\end{array}$ \\
\hline $\begin{array}{l}\text { 1. Etching } \\
\text { Apply for } 15 \text { seconds, } \\
\text { rinse } 15 \text { seconds gently } \\
\text { air dry, while keeping } \\
\text { dentin moist. }\end{array}$ & $\begin{array}{l}\text { 1.Etching } \\
\text { Apply for } 15 \text { seconds } \\
\text { followed by } \\
\text { Rinsing for } 15 \text { seconds, } \\
\text { and gently air-dry while } \\
\text { keeping dentin moist. }\end{array}$ & $\begin{array}{l}\text { 1. Etch and Prime } \\
\text { One application without } \\
\text { rinsing, gently air-dry. }\end{array}$ & $\begin{array}{l}\text { 1. Etch, Prime, and } \\
\text { Bond } \\
\text { Apply } 1 \text { to } 5 \text { layers with- } \\
\text { out rinsing, gently air- } \\
\text { dry, a light cure. }\end{array}$ \\
\hline $\begin{array}{l}\text { 2. Primer application } \\
\text { Apply } 1 \text { to } 5 \text { layers, gen- } \\
\text { tly air- dry. }\end{array}$ & $\begin{array}{l}\text { 2.Prime and Bond } \\
\text { Apply } 1 \text { to } 5 \text { layers, } \\
\text { Gently air-dry, a light } \\
\text { cure. }\end{array}$ & $\begin{array}{l}\text { 2. Bond } \\
\text { Apply one layer, gently } \\
\text { air-dry, a light cure. }\end{array}$ & \\
\hline \multicolumn{4}{|l|}{$\begin{array}{l}\text { 3. Bond agent applica- } \\
\text { tion } \\
\text { Apply one layer of adhe- } \\
\text { sive, followed by light } \\
\text { curing. }\end{array}$} \\
\hline $\begin{array}{l}\text { Generations of bond- } \\
\text { ing agents }\end{array}$ & Number of components & $\begin{array}{l}\text { Number of steps } \\
\text { required }\end{array}$ & $\begin{array}{c}\text { Shear bond strength } \\
\text { (MPa) }\end{array}$ \\
\hline First-generation & 2 & 2 & 2 \\
\hline Second-generation & 2 & 2 & 5 \\
\hline Third-generation & $2-3$ & 3 & 12 \\
\hline Fourth-generation & $3-5$ & 3 & 24 \\
\hline Fifth-generation & 2 & 2 & 25 \\
\hline Sixth-generation & 2 & $1-2$ & 20 \\
\hline Seventh- generation & 1 & 1 & 25 \\
\hline Eighth-generation & 1 & 1 & $30-38$ \\
\hline
\end{tabular}

\subsubsection{Sixth-generation bonding agents}

These generation systems consist of two different types which are discussed in subsequent sections.

\subsubsection{Self-etching primer}

It is an aqueous solution of $20 \%$ of phenyl-p in $30 \%$ HEMA for bonding to enamel and dentin simultaneously. The combination of etching and priming steps reduces the working time, eliminates washing out of the acid gel and also eliminates the risk of collagen collapse [2].

\subsubsection{Self-etching adhesives:}

These are all-in-one adhesives contain acidic unreacted monomer that contacts the composite restorative material directly. The etching, priming, and bonding agents together in a single solution are now available commercially. However, the dentin bond strengths of these systems are lower than those obtained with total-etch adhesives [21]. Kallenos et al. (2005) [21] and Al-Ehaideb et al. (2001) [22] observed no significant differences in tensile bond strength and microleakage between the sixth and fifth-generation systems. Commercial systems available are Adper Prompt L - Pop 
(3M ESPE), One - Up Bond F (Tokuyama Dental), Xeno III (Dentsply).

\subsubsection{Composition}

Adper Prompt L - Pop-Adhesive: 2 HEMA, Bis GMA, methacrylate phosphoric Esters, 1,6-hexanidoldimethacrylate, methacrylate functionalized polyalkenesAcid, camphorquinone, ethanol, water, silica filler, and stabilizer [23].

\subsubsection{Seventh-generation bonding agents}

The latest generation which combines etch, primer, and bond in a single solution. It is a single-step procedure or "All - in - one". Clinicians consider using onestep, self-etch adhesives are attractive approach since they require reduced and less complex number of clinical steps compared with multistep etch-and -rinse adhesives [2]. Commercial materials available with seventh-generation adhesives are ibond (Heraeuskulzer), Xeno IV (Dentsply), Optibond All -in -one (Kerr).

The permeability of cured adhesive permits migration of water from underlying dentin and forms water blisters along the composite-adhesive interface. The increase in hydrophilicity encourages better diffusion of the low-viscosity dentin bonding agent into the evacuated spaces created by the acid etching process. As a result, water is incorporated in the shape of trees in the hybrid zone. These blisters can act as stress raisers that lower bond strength of chemical cured composite to dentin. These blisters may be identified as black deposits on immersing in silver nitrate tracer solution. The shelf life and bond strength are decreased due to the water permeability from dentin around the resin tags [24].

\subsubsection{Composition of seventh-generation adhe- sives}

G-BOND: 4 META, UDMA, phosphate monomer, DMA component, fumed silica filler, acetone, water, photoinitiator.

Clear I S3: MDP, bis-GMA, HEMA, water, ethanol APXClearfil.

One Coat7.0: UDMA, HEMA, glycerol-dimethacrylate, polyakenoate methacrylate, and amorphous silica, ethanol.

Xeno V: Bifunctional acrylamides, acrylamide alkyl sulfonic acid, inverse functional phosphoric acid ester, acrylic acid, butylated benzenediol, water, tert-butanol camphoroquinone.

Optibond all in one: Glycerol phosphate dimethacrylate, mono- and di-functional methacrylate esters, water, acetone, ethanol [20].

\subsubsection{Eighth-generation bonding agents}

In 2010, Voco America introduced Voco futura bond DC as an 8th generation bonding agent, which contains nanosized fillers [25]. Nano-fillers with an approximate particle size of $12 \mathrm{~nm}$ are incorporated in these new systems. These nano-fillers facilitate increased penetration of resin monomers and the thickness of the hybrid layer that, in turn, results in improving the mechanical properties of the bonding systems $[26,27]$. Further, nano-bonding agent solutions with nanofillers produce better enamel and dentin bond strength, stress absorption, and longer shelf life [28]. These new agents from self-etch generations have acidic hydrophilic monomers which can be easily applied on the moistened and etched enamel [29].

The concentration and the size of the nano-fillers may influence the viscosity of the adhesive resins. It was reported that the filler sizes larger than $15-20 \mathrm{~nm}$ and the content with more than $1.0 \%$ by weight may increase the viscosity of the adhesives and also results in agglomeration of the fillers on the moistened surface. These clusters can act as flaws that may induce cracks and cause a decrease in bond strength [27]. Numerous studies reported more shear bond strength compared to previous generation bonding agents [30-35]. The shear bond strengths of all eighth-generation bonding agents were described in table 3 .

Composition of eight-generation bonding agents includes; a unique combination of three functional monomers (4-META, MDP, and MDTP), notably excluding HEMA, ensures excellent stability and exceptional bond strengths not just to tooth tissue but to all indirect substrates, including composites, precious and non-precious alloys.

\subsubsection{Commercial products}

G-Premio bond, GC Corporation, USA.

All Bond Universal, Bisco Dental, USA. 


\section{Conclusion}

Dentin bonding agents have dramatically improved in recent years. The major breakthrough has been the "total-etch" technique, in which the smear layer is removed simultaneously with the enamel etching. The primers and bonding agents of multicomponent systems and a combined primer/agent of one-bottle systems provide a dramatic bond to both the collagen and etched hydroxyapatite of the dentin. Although dentin bonding agents are not yet considered "ideal" materials, they are certainly close. The new adhesive systems also can be attributed to their ability to decrease or eliminate postoperative sensitivity, improve the marginal seal, reduce microleakage and enhance the flow of resin into the fissures. The development of functional monomers with strong and stable chemical affinity to hydroxyapatite is, without doubt, a valuable direction to continue for improvement of dental adhesion.

Furthermore, long-term ageing also requires evaluation of its effect in establishing a long-term success of the composite restoration. Hopefully, more controlled clinical trials will be forthcoming, allowing choices of material and technique to be made on a sound scientific basis. Research continues, and each new generation product comes closer to perfection.

\section{Abbreviations}

BIS-GMA - Bisphenyl glycidyl methacrylate, HEMA Hydroxyethyl methacrylate, NPG-GMA - Reaction product of $\mathrm{N}$-phenyl glycin-glycidyl methacrylate, PMDM - Reaction product of Pyromellitic acid and 2hydroxyethyl methacrylate, UDMA - Urethane dimethacrylate, META - Methacryloxy-ethyl trimellitate anhydride, NTG-GMA - Reaction product of N-Ptolyglycine and glycidyl methacrylate, BPDM - Bimethyldimethacrylate, 5-NMSA - N-methacryloyl-5aminosalicylic acid, PENTA - Di penta erythritol peta acrylate monophosphate.

\section{References}

1. Ravi RK, Rama Krishna Alla, Shammas M, Devarhubli A, Dental Composite - A Versatile Restorative Material: An Overview. Ind J Dent Sci. 2013; 5(5):111-115.
2. Alla RK, Composite Resins (Tooth colored restorative materials) in; Dental Materials Science, Jaypee Brothers Medical Publishers (P) Ltd., New Delhi, India, 2013; 132-148.

3. Ferracane JL. Current trends in dental composites. Crit Rev Oral Biol Med. 1995; 6: 302-18.

4. Fleisch AF, Sheffield PE, Chinn C, Edelstein BL, Landrigan PJ. Bisphenol A and Related Compounds in Dental Materials. Pediatrics 2010; 126:760-8.

5. Anusavice KJ, Shen C, Ralph Rawls H. Bonding and bonding agents; in Phillip's Science of Dental Materials: 12th edition, Elsevier Saunders, USA. 258 284.

6. Erickson RL. Surface interaction of dentin adhesive system. Oper Dent. 1992; 5 (suppl): 81-94.

7. Sofan E, Sofan A, Palaia A, Tenore G, Romeo U, Migliau G. Classification review of dental adhesive systems: from the IV generation to the universal type.Annali di Stomatologia2017;VIII (1):1-17 $1 \mathrm{~s}$

8. Buonocore M, Marsui A, Gwinnett AJ. Penetration of resin dental materials into enamel surfaces with reference to bonding. Arch Oral Biol. 1968;13 (1):61-70.

9. Swift E Jr, Perdigao J, Heymann H. Bonding to enamel and dentin: a brief history and state of the art. Quintessence Int. 1995;26:95-110.

10. Eick J, Wilko R, Anderson C, Sorensen S. Scanning electron microscopy of cut tooth surfaces and identification of debris by use of the electron microprobe. J Dent Res. 1970;49:1359-1368.

11. Nakabayashi N, Kojima K, Masuhara E. The promotion of adhesion by the infiltration of monomers into tooth substrates. J Biomed Mater Res. 1982;16 (3):265-273

12. Latta MA, Barkmeier WW. Dental adhesives in contemporary restorative dentistry. DCNA. 1998;42 (4):567-577.

13. Kugel G, Ferrari M. The science of bonding from first to sixth generation. J Am Dent Assoc 2000;131 Suppl:20S-25S.

14. Kanca J, Improving Bond Strength Through Acid Etching of Dentin and Bonding to Wet Dentin Surfaces, J Am Dent Assoc. 1992; 123(9):35-43.

15. Tay FR, Gwinnett AJ, Pang KM, Wei SH. Structural evidence of a sealed tissue interface with a totaletch wet-bonding technique in vivo. J Dent Res.1994; 73(3):629-36.

16. Ruyter IE. The chemistry of adhesive agents. Oper Dent. 1992; 5 (suppl): 32-43.

17. Tay FR, Gwinnett AJ, Pang KM, et al. Resin permeation acid conditioned, moist and dry dentin: A par- 
adigm using water free adhesive primers. J Dent Res. 1996;75: 1033-1044.

18. Poptani B, Gohil KS, JaishreeGanjiwale, Manisha Shukla. Microtensile dentin bond strength of fifthwith five seventh-generation bonding agents after thermocycling: An in vitro study. Contemp Clin Dent. 2012;3: S167-71.

19. Alex G. Adhesive considerations in the placement of direct composite restorations. Compend. 2008;1(1):20-25.

20. Kallenos TN, Al-Badawi E, White GE. An in vitro evaluation of microleakage in class I preparations using 5th, 6th, and 7th generation composite bonding agents. J Clin Pediatr Dent 2005; 29: 323-8.

21. Al-Ehaideb AA, Mohammed H. Microleakage of one bottle dentin adhesives. Oper Dent. 2001; 26: 172-5.

22. Hegde \& Manjunath. Bond Strength of Newer Dentin Bonding Agents to Altered Dentin Surfaces. Operative Dentistry. 2011;36(2):169-176

23. Pashley DH, Tay FR. The aggressiveness of contemporary self-etching adhesives. Part II: Etching effects on unground enamel. Dent Master. 2001;17(5):430-444.

24. Freedman G. in Contemporary Esthetic Dentistry, Adhesion, Mosby, 2012: 168-213

25. Başaran G, Ozer T, Devecioğlu Kama J. Comparison of a recently developed nanofiller self-etching primer adhesive with other self-etching primers and conventional acid etching. Eur J Orthod. 2009;31 (3):271-275.

26. Kasraei SH, Atai M, Khamverdi Z, KhaleghNejad S. Effect of nanofiller addition to an experimental dentin adhesive on microtensile bond strength to human dentin. J Dent (Tehran) 2009;6(:91-96.

27. Joseph P, Yadav C, Satheesh K, Rahna R. Comparative evaluation of the bonding efficacy of sixth, seventh and eighth generation bonding agents: An in vitro study. Int Res J Pharm. 2013;4(9):143147.

28. Nogourani MK, NejadSh J, Homayunzadeh M. Sealant Microleakage in Saliva-Contaminated Enamel: Comparison between three adhesive systems. J Dent Sch. 2010; 27(4): 197-204.

29. Townsend RD, Dunn WJ.The effect of saliva contamination on enamel and dentin using a selfetching adhesive. J Am Dent Assoc. 2004;135(7): 895-901.

30. Ibarra, Gabriela Vargas, Marcos A, Armstrong, Steve R, Cobb, Deborah S. Microtensile Bond strength of Self-etching Adhesives to Ground and Unground Enamel. Journal of Adhesive Dentistry. 2002; 4(2): 115-124.

31. Deepa VL, Damaraju B, Priyadharsini BI, Subbarao VV, Raju KR. Comparative evaluation of microshear bond strength of 5th, 6th and 7th) generation bonding agents to coronal dentin versus dentin at floor of pulp chamber: An in vitro Study. J Int Oral Health. 2014;6(5):72-6.

32. Nikhil V, Singh V, Chaudhry S. Comparative evaluation of bond strength of three contemporary selfetch adhesives: An ex-vivo study. Contemp Clin Dent. 2011; 2(2): 94-7.

33. Yaseen SM, Subba Reddy VV. Comparative evaluation of shear bond strength of two self-etching adhesives (sixth and seventh generation) on dentin of primary and permanent teeth: An in vitro study. J Indian Soc PedodonPrev Dent. 2009; 27(1):33-8.

34. Nair M, Paul J, Kumar S, Chakravarthy Y, Krishna V, Shivaprasad Comparative evaluation of the bonding efficacy of sixth and seventh generation bonding agents: An in-vitro study. J Conserv Dent. 2014; 17(1):27-30.

35. Shekar R, Ponnappa KC, Mirdha N, Narula S. To evaluate and compare the shear bond strength of fifth (total etch) generation, sixth (two step, selfetch adhesive) generation and seventh (one step, self-etch adhesive) generation dentin bonding agents. Natl Res Denticon. 2013;2(2):136-43. 